Original Research Article

\title{
Study of antimicrobial prescribing pattern in a tertiary care teaching hospital at Dehradun, Uttarakhand, India - A tool to teach clinical pharmacology to MBBS students
}

\author{
Mirza Atif Beg*, Shalu Bawa, Shaktibala Dutta, Mohammad Anjoom, Subhash Vishal
}

Department of Pharmacology, Shri Guru Ram Rai Institute of Medical and Health Sciences, Patel Nagar, Dehradun, Uttarakhand, India

Received: 12 September 2016 Accepted: 15 October 2016

\section{*Correspondence to:}

Dr. Mirza Atif Beg,

Email: mabeg1997@gmail.com

Copyright: (C) the author(s), publisher and licensee Medip Academy. This is an openaccess article distributed under the terms of the Creative Commons Attribution NonCommercial License, which permits unrestricted noncommercial use, distribution, and reproduction in any medium, provided the original work is properly cited.

\begin{abstract}
Background: Due to increasing resistance to a majority of antimicrobials, it becomes very necessary to teach undergraduate students, the future prescribers, about the judicious and rational use of antimicrobial drugs. The objective of this study was to impart the basic clinical skills to undergraduate MBBS students which will form an integral component of practising rational therapeutics.

Methods: A total no of 737 cases were followed up by the 5th semester 2 nd Professional MBBS students in the Department of Pharmacology at Shri Guru Ram Rai Institute of Medical and Health Sciences (SGRRIM and HS), Dehradun from June 2013 to July 2015. Patients were analysed on various WHO drug use indicators like drug formulations, drugs prescribed per prescription, Fixed dose Combinations (FDCs), drugs prescribed from National List of Essential Medicines (NLEM) and drugs prescribed by generic names.

Results: A total of 737 prescriptions were analysed. Male: Female ratio was 1.74:1 (63.50\%:36.50\%). Majority of the patients $218(29.58 \%)$ were in 16-30 years age group. A total of 1205 antimicrobials were prescribed. 304 (25.23\%) cephalosporins were most frequent followed by $184(15.27 \%)$ penicillins, $176(14.61 \%)$ antitubercular drugs, 163(13.53\%) nitroimidazoles, $143(11.87 \%)$ fluoroquinolones, $102(8.46 \%)$ aminoglycosides, $29(2.41 \%)$ macrolides, 19 $(1.58 \%)$ tetracyclines, $12(1 \%)$ carbapenems, $11(0.91 \%)$ antimalarials, 11 $(0.91 \%)$ antihelminthics, $6(0.50 \%)$ glycopeptides, $4(0.33 \%)$ lincosamides and $41(3.41 \%)$ miscellaneous antimicrobials. Most frequently prescribed antimicrobial was Ceftriaxone which was given in $97(8.05 \%)$ patients. A total of $424(35.19 \%)$ oral antimicrobials, $777(64.48 \%)$ injectable antimicrobials and $04(0.33 \%)$ local/topical antimicrobial drugs were prescribed. 5.13 drugs per prescription and 1.64 antimicrobials per prescription were prescribed. 2100 $(55.56 \%)$ drugs were prescribed from National List of Essential Medicine 2015 (NLEM 2015). 1177 (97.68\%) antimicrobials were prescribed from NLEM. $1110(92.12 \%)$ antimicrobials were prescribed by brand names. A total of 342 (28.38\%); fixed dose combinations of antimicrobials were prescribed.

Conclusions: Majority of the prescriptions revealed poly-pharmacy and a very high percentage of drugs were prescribed by their respective brand names. It is only by observing drug utilization patterns, current trends and common errors in prescriptions can be highlighted and rational prescription of antimicrobials can be taught to MBBS students.
\end{abstract}

Keywords: Antimicrobials, Prescribing pattern, WHO drug use indicators, Rational prescription

\section{INTRODUCTION}

Antibiotics are the most frequently prescribed drugs among hospitalized patients. ${ }^{1}$ The prevalence of antibiotic use is very high in India and ranges from 24 to $67 \% .^{2}$ Recently, Schedule H1 was introduced in India under the existent Drug and Cosmetic Act 1945 by the regulatory agencies to control the irrational prescribing of antibiotics. $^{3}$ Irrational antibiotic usage can lead to increased healthcare utilization, morbidity, mortality, adverse drug events and antimicrobial resistance. ${ }^{4}$ 
Several authors have reported concern about the continuous indiscriminate and excessive use of antimicrobial agents that promote the emergence of antimicrobial resistant organisms. The global spread of antimicrobial resistance has become a pressing problem, due to the increasing administration of ineffective antimicrobial regimens associated with greater morbidity and mortality. ${ }^{5,6}$ Programs designed to encourage appropriate antibiotic prescriptions in health institutions are an important element in quality of care, infection control and cost containment. Monitoring of antimicrobial use and knowledge of prescription habits are some of the strategies recommended to contain resistance to antimicrobials in hospitalized patients. ${ }^{1}$

The WHO sponsored survey on teaching clinical pharmacology in medical colleges in India has shown that in order to improve rational prescribing of medicines, clinical pharmacology should be introduced at the undergraduate level. The broad goal of teaching undergraduates clinical pharmacology is to impart the knowledge, skills and attitudes that a student should learn in order to prescribe drugs safely and effectively and to maintain this competence throughout his/her professional life. ${ }^{7}$ As MBBS students are future prescribers, it is very necessary to teach them about the appropriate and rational use of antimicrobial agents. This study was conducted to observe, highlight and teach MBBS students the current antimicrobial prescribing pattern which would further help them in rational prescribing.

\section{METHODS}

This cross-sectional study was conducted in Shri Guru Ram Rai Institute of Medical and Health Sciences (SGRRIM and HS) Dehradun where $2^{\text {nd }}$ professional undergraduate MBBS students collected prescriptions of in-patients from hospital wards during their clinical postings. The data obtained was arranged, categorised and analysed in the Department of Pharmacology for trends of antimicrobial use and rationality of prescriptions. Approval of the Institutional Ethics Committee was obtained prior to the commencement of the study. A total of 737 prescriptions were collected and analysed in the Department of Pharmacology at SGRRIM and HS, Dehradun from June 2013 to July 2015.

The WHO indicators which were analysed were: Drug Formulations, drugs prescribed from National List of Essential Medicines (NLEM) 2015, Generic drugs and drugs prescribed per prescription.

\section{RESULTS}

A total of 737 prescriptions were analysed. Male: Female ratio was $1.74: 1 \quad(63.50 \%: 36.50 \%)$. Majority of the patients $218(29.58 \%)$ were in 16-30 years age, followed by $201(27.27 \%)$ in $31-45$ years, $156(21.17 \%)$ in $46-60$ years, $97(13.16 \%)$ in $0-15$ years and $65(8.82 \%)$ in $>60$ years age group (Table 1). A total of 3750 drugs were prescribed out of which $1205 \quad$ (32.13\%) were antimicrobials. A total of 737 patients were categorised according to diseases like Respiratory tract infections which consisted of $275(37.31 \%)$ patients followed by $205(27.81 \%)$ gastrointestinal infections, $100(13.56 \%)$ genitourinary infections, $99(13.43 \%)$ pyrexia of unknown origin (PUO), $38(5.15 \%)$ surgical infections and $20(2.71 \%)$ patients in miscellaneous category were included (Figure 1).

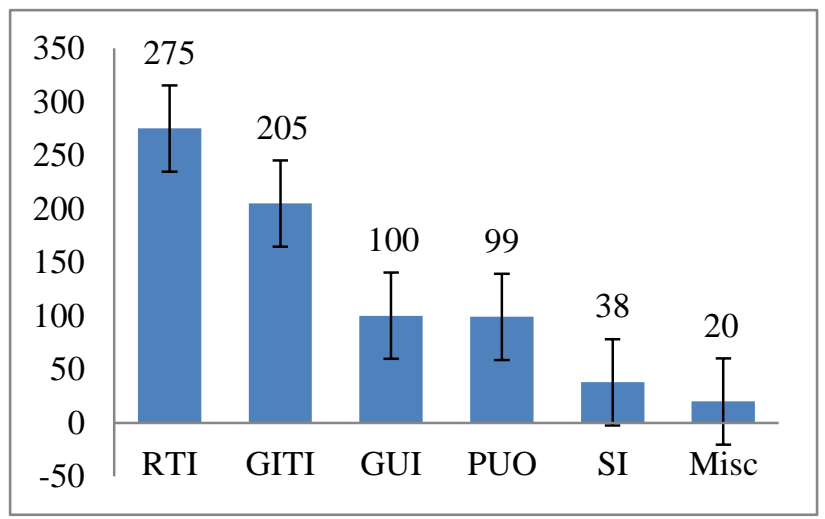

RTI: Respiratory tract infection; GITI: Gastro-intestinal tract infection; GUI: Genito-urinary infection; PUO: Pyrexia of unknown origin; SI: Surgical infection; Misc: Miscellaneous.

Figure 1: Disease pattern.

Table 1: Age wise distribution.

\begin{tabular}{|ll|}
\hline Parameters & Number (Percentage) \\
\hline $0-15$ years & $97(13.16 \%)$ \\
\hline $16-30$ years & $218(29.58 \%)$ \\
\hline $31-45$ years & $201(27.27 \%)$ \\
\hline 46-60 years & $156(21.17 \%)$ \\
\hline$>60$ years & $65(8.82 \%)$ \\
\hline
\end{tabular}

Table 2: Most commonly prescribed antimicrobials.

\begin{tabular}{|l|l|}
\hline Name of drug & No. of patients \\
\hline Ceftriaxone & $97(8.05 \%)$ \\
\hline Piperacilin + Tazobactam & $73(6.06 \%)$ \\
\hline Amoxicillin + Clavulanic acid & $71(5.89 \%)$ \\
\hline Amikacin & $62(5.14 \%)$ \\
\hline Cefoperazone + Sulbactam & $54(4.48 \%)$ \\
\hline
\end{tabular}

Table 3: Other parameters.

\begin{tabular}{|ll|}
\hline Drugs per prescription & $\mathbf{5 . 1 3}$ \\
\hline Antimicrobials per prescription & 1.64 \\
\hline $\begin{array}{l}\text { Antimicrobials from NLEM } \\
2015\end{array}$ & $1177(97.68 \%)$ \\
\hline $\begin{array}{l}\text { Antimicrobials prescribed by } \\
\text { brand names }\end{array}$ & $1110(92.12 \%)$ \\
\hline $\begin{array}{l}\text { Fixed dose combinations (FDCs) } \\
\text { of antimicrobials }\end{array}$ & $342(28.38 \%)$ \\
\hline
\end{tabular}




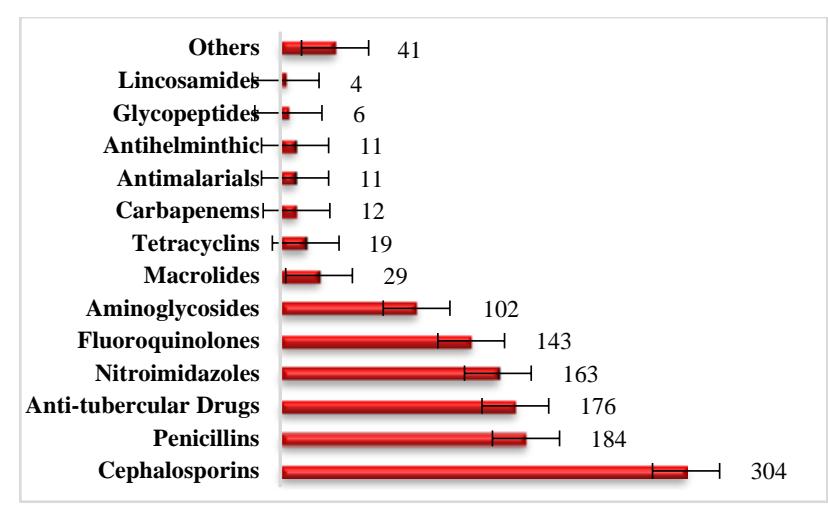

Figure 2: Antimicrobial prescribing pattern.

Amongst antimicrobials, 304 (25.23\%) cephalosporins were most frequently prescribed, followed by 184 (15.27\%) penicillins, $176(14.61 \%)$ antitubercular drugs, $163(13.53 \%) \quad$ nitroimidazoles, $143 \quad(11.87 \%)$ fluoroquinolones, $102(8.46 \%)$ aminoglycosides, 29 (2.41\%) macrolides, $19(1.58 \%)$ tetracyclines, $12(1 \%)$ carbapenems, $11(0.91 \%)$ antimalarials, $11(0.91 \%)$ antihelminthics, $6(0.50 \%)$ glycopeptides, $4(0.33 \%)$ lincosamides $41(3.41 \%)$ miscellaneous antimicrobials were prescribed (Figure 2). Most frequently prescribed antimicrobials were Ceftriaxone in $97(8.05 \%)$ patients, followed by Piperacillin + Tazobactum in 73 (6.06 \%), Amoxicillin + Clavulanic acid in 71 (5.89\%), Amikacin in $62(5.14 \%)$ and Cefoperazone + Sulbactam in 54 $(4.48 \%)$ patients (Table 2 ).

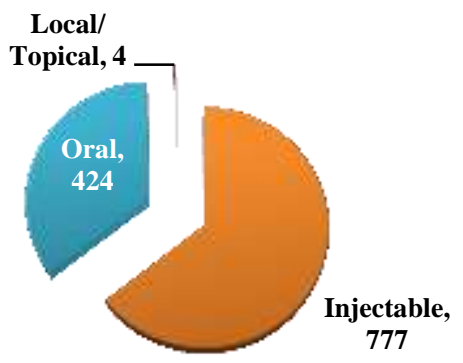

Figure 3: Dosage form of antimicrobials.

A total of $424(35.19 \%)$ oral antimicrobials, 777 $(64.48 \%)$ injectable antimicrobials and $4(0.33 \%)$ local/topical antimicrobial drugs were prescribed (Figure 3). 5.13 drugs per prescription and 1.64 antimicrobials per prescription were prescribed. 1177 (97.68\%) antimicrobials were prescribed from NLEM 2015. 1110 $(92.12 \%)$ antimicrobials were prescribed by brand names. A total of $342(28.38 \%)$ fixed dose combinations of antimicrobials were prescribed (Table 3 ).

\section{DISCUSSION}

Prescription monitoring studies are important for obtaining data about the patterns and quality of use, the determinants of drug use, and the outcomes of use. The WHO drug use indicators are highly standardized and are recommended for inclusion in drug utilization studies. ${ }^{8}$ Antimicrobial resistance is one of the major global preventable problems. The causes of antimicrobial resistance are unnecessary use, inappropriate doses, inadequate duration of therapy and irrational fixed dose drug combinations. ${ }^{9}$

Since MBBS students are future prescribers, the present study was an attempt to develop clinical skills in MBBS second professional students and develop skills in rational prescribing.

In this study, antimicrobial prescribing pattern was analyzed in 737 prescriptions. There were more male patients as compared to females. This was comparable with previous studies. ${ }^{10,11}$ The reason for more male admissions in our study may be that female patients are reluctant to utilize health care facilities unless they are critically ill. Majority of the patients belonged to 16-30 year age group. This was similar to earlier studies where most of the patients in whom antimicrobials were prescribed belonged to $16-30$ years of age group. ${ }^{12,13}$ Majority of the patients were suffering from respiratory tract infections in our study. This was similar as previous studies indicating that respiratory tract infections dominate amongst all infections. ${ }^{2,14}$ Cephalosporins were the most frequently prescribed antimicrobials in our study followed by Penicillins. This pattern has been seen in previous studies. ${ }^{2,15}$ This may be because Cephalosporins are broad spectrum antimicrobials effective against vast majority of organisms, have convenient dosing schedules and have fewer adverse effects; hence they are being prescribed more frequently both in wards and out-patient clinics. This may be one of the reasons for growing cephalosporin resistance in this region. ${ }^{16}$ Penicillins were the second most commonly prescribed drugs in our study. This is corresponding with the previous studies which have shown the high use of Penicillins. ${ }^{17,18}$ The commonest antimicrobial in our study was Ceftriaxone; this is in accordance with previous studies, where Ceftriaxone was most commonly prescribed. ${ }^{2,15,19}$ Ceftriaxone is a third generation injectable cephalosporin and shows sensitivity towards large number of organisms.

Most of the antimicrobials were given in injectable form $(64.48 \%)$ indicating the seriousness of the infections. This was dissimilar to previous studies where majority of antimicrobials were given by oral route. ${ }^{20,21}$ Most of the prescriptions were collected from the wards; this may be the reason for prescribing more injectable formulations.

Average number of drugs per person is an important index of prescription audit. Mean number of drugs per prescription should be kept as low as possible. Higher figures (polypharmacy) always lead to increased risk of drug interaction, adverse effects, development of bacterial resistance, increased hospital cost. ${ }^{22}$ In our study the average number of drugs per prescription was 5.13. 
This was comparable to a study from Western Nepal which recorded a mean of 5.1, and was less than other study by Lisha et al. ${ }^{23,24}$

In our study the average number of drugs per prescription was 5.13, indicating polypharmacy. The average number of antimicrobials per prescription was 1.64 which is higher than previous study, where number of antimicrobials per prescription was $1.24 .^{14}$ Number of antimicrobials per prescription should be kept low to prevent antimicrobial resistance. Majority of the antimicrobials were prescribed by their respective brand names. Use of generic drugs has declined over the years and this issue must be dealt seriously. Increased use of brand names has been found in earlier studies too. ${ }^{25,26} \mathrm{~A}$ total of $28.38 \%$ Fixed dose combinations (FDCs) were prescribed. This was comparable with a previous study where $29.18 \%$ FDCs were used. ${ }^{27}$ Majority of antimicrobials were prescribed from National List of Essential Medicines (NLEM) 2015. This was similar to a previous study. ${ }^{28}$

To summarise our findings, $2^{\text {nd }}$ professional undergraduate MBBS students collected prescriptions of in-patients from hospital wards which were analysed on various WHO parameters. The results showed that out of 737 prescriptions, majority were male, Most of the prescriptions were of patients in 16-30 year age group, and a total of 1205 antimicrobials were prescribed. The leading infections were respiratory tract infections, cephalosporins were the most frequently prescribed antimicrobials followed by penicillins. Ceftriaxone was the most frequently prescribed antimicrobial. Most of the medicines were given in injectable form. Majority of the drugs were from NLEM 2015. The number of drugs per prescription was 5.13 indicating polypharmacy. The Antimicrobials per prescription was 1.64 and most of the drugs were given by their respective brand names.

The limitations of this study were the inability on the part of students to report adverse drug reactions and various drug interactions associated with antimicrobials.

\section{CONCLUSION}

The worldwide increase in antimicrobial resistant bacteria is of great concern and it is the responsibility of the doctors to develop good prescribing habits which will help in reducing the intensity of the problem. Since MBBS students are future prescribers, we should develop prescribing skills in them to promote judicious use of antimicrobials.

\section{Funding: No funding sources} Conflict of interest: None declared

Ethical approval: The study was approved by the Institutional Ethics Committee

\section{REFERENCES}

1. Badar VA, Navale SB. Study of Prescribing Pattern of Antimicrobial Agents in Medicine Intensive Care Unit of a Teaching Hospital in Central India. JAPI. 2012;60:20-3.

2. Ahmad A, Revanker M, Haque I, Pravina A, Ivan R, Dasari R, et al. Study the Prescription Pattern of Antibiotics in the Medicine Department in a Teaching Hospital: A Descriptive Study International Journal of Toxicological and Pharmacological Research. 2014;6(2):43-6.

3. Ahmad A, Patel I. Schedule H1: Is it a Solution to Curve Antimicrobial Misuse in India? Annals of Medical and Health Sciences Research. 2013;3(1):55-6.

4. Rehana HS, Nagarani MA, Rehan M. A study on the drug prescribing pattern and use of antimicrobial agents at a tertiary care teaching hospital in eastern Nepal. Indian J Pharmacol. 1998;30:175-80.

5. Morata L, Cobos-Trigueros N, Martinez JA, Soriano A, Almela M, Marco F, et al. Influence of multidrug resistance and appropriate empirical therapy on the 30-day mortality rate of Pseudomonas aeruginosa bacteremia, Antimicrob Agents Chemother. 2012;56:4833-7.

6. Ahmed MM, Maraghy AA, Andrawas EW. Study of prescription patterns of antibiotics in treating lower respiratory tract infections at Sohag Chest Hospital. Egypt. J Chest Dis Tuberc. 2015:1-13.

7. Dutta SB, Beg MA. Clinical Case Follow Up Study: A Method of Teaching Clinical Pharmacology to the MBBS Students. Research and Reviews: Journal of Pharmacology and Toxicological studies. 2014;2(2):40-4.

8. Dutta SB, Beg MA, Bawa S, Kaur A. Drug utilization study in genitourinary infections used as a teaching tool for rational therapy for MBBS students in a Medical College at Dehradun, Uttarakhand. IJBCP. 2015;4(2):236-9.

9. Selvaraj R. Prospective assessment of antimicrobial prescribing pattern at a tertiary care hospital $\mathrm{Al}$ Ameen. J Med Sci. 2015;8(4):276-80.

10. Williams A, Mathai AS, and Phillips AS. Antibiotic prescription patterns at admission into a tertiary level intensive care unit in Northern India. J Pharm Bioallied Sci. 2011;3(4):531-6.

11. Shankar RP, Partha P, Shenoy NK, Easow JM, Brahmadathan K. Annals of Clinical Microbiology and Antimicrobials. 2003;2:7.

12. Salman JM, Alawi S, Alyusuf E, Albasri E, Almarzooq S, Alnashaba F, et al. Patterns of antibiotic prescriptions and appropriateness in the emergency room in a major secondary care hospital in Bahrain. The International Arabic Journal of Antimicrobial agents. 2015;5(3):1-8.

13. Gafar A, Emmanuel UE, Zuwaira S, Hudu A. The pattern of antibiotic use in a family medicine department of a tertiary hospital in Sokoto, North 
Western Nigeria. Journal of Clinical and Diagnostic Research. 2011;5(3):566-9.

14. Choudhury D, Deka A, Roy D. Pattern of Antibiotics Used in the Pediatrics Indoor Department at Silchar Medical College and Hospital, Assam, India. Sch J App Med Sci. 2015;3(4C):1810-4.

15. Pandiamunian J, Somasundaram G. Study on prescribing pattern of Anti-microbial agents in the Medical Intensive Care Unit of a Tertiary Care Teaching hospital in Puducherry union territory, South India. Int J Pharm Sci. 2014;6(3):235-8.

16. Dancer SJ. Problem with cephalosporins. J Antimicrob Chemother. 2001;48(4):463-78.

17. Khan FA, Singh VK, Sharma S, Singh P. Prospective Study on the Antimicrobial Usage in the Medicine Department of a Tertiary Care Teaching Hospital. JCDR. 2013;7(7):1343-6.

18. Das BP, Sethi A, Rauniar GP, Sharma SK. Antimicrobial utilization pattern in outpatient services of ENT department of tertiary care hospital of Eastern Nepal. Kathmandu Univ Med J. 2005;3:370-5.

19. Hanssens Y, Ismaeili BB. Antibiotic prescription pattern in a medical intensive care unit in Qatar. Saudi Med J. 2005;26:1269-76.

20. Getachew E, Aragaw S, Adissie A, Agalu A. Antibiotic prescribing pattern in a referral hospital in Ethiopia Global Journal of Pharmacy and Pharmacology. 2013;1(1):078-082.
21. Takhar P, Yadav S, Dua S, Mahant S. Investigation of antibiotic usage pattern: A prospective drug utilization review. Scholars Research Library Der Pharmacia Lettre. 2011:3(5)301-6.

22. Stratton CW, Ratner H, Johnston PE, Schaffner W. Focused microbiological surveillance by specific hospital unit: practical application and clinical utility. Clin Ther. 1993;15(SupplA):12-20.

23. Shankar PR, Partha P, Shenoy NK, Easow JM, Brahmadathan KN. Prescribing patterns of antibiotics and sensitivity patterns of common microorganisms in the Internal Medicine ward of a teaching hospital in Western Nepal: a prospective study. Ann Clin Microbiol Antimicrob. 2003;16;2:7.

24. Lisha JJ, Padmini D, Jenny J, Shoba G. Drug Utilization Study of Antimicrobial agents in Medical intensive care unit of a tertiary care hospital. Asian $\mathbf{J}$ Pharm Clin Res. 2011;4(2):81-4.

25. Saurabh MK, Jaykaran, Yadav AK, Jyoti N. Study of prescribing pattern and assessment of rational use of drugs in tertiary hospital, Rajasthan. J Pharm Res. 2010;3(3):474-7.

26. Patel V, Vaidya R, Naik D, Borker P. Irrational drug use in India: A prescription survey from Goa. J Postgrad Med. 2005;51:9-12.

27. Hiware SK, Mahatme MS, Dudhgaonkar SD, Deshmukh SN, Mahajan PD. Prescription pattern of antimicrobials in tertiary care hospital in central India. MMIJPR. 2015;5 (2):31-4.

Cite this article as: Beg MA, Bawa S, Dutta S, Anjoom M, Vishal S. Study of antimicrobial prescribing pattern in a tertiary care teaching hospital at Dehradun, Uttarakhand, India - A tool to teach clinical pharmacology to MBBS students. Int J Basic Clin Pharmacol 2016;5:2444-8. 